http://dx.doi.org/10.1590/0370-44672019730167

\begin{abstract}
Jacopo Seccatore ${ }^{1,2}$
https://orcid.org/0000-0003-4619-1124

Patricio Gonzalez ${ }^{1,3}$

https://orcid.org/0000-0001-9493-4012

Miguel Herrera ${ }^{1,4}$

https://orcid.org/0000-0002-7472-391X

${ }^{1}$ Universidad Adolfo Ibáñez,Facultad de Ingeniería y Ciencias, Penalolen - Chile.
\end{abstract}

E-mails: ${ }^{2}$ jacopo.seccatore@uai.cl,

33patricgonzalez@alumnosuaicl.onmicrosoft.com,

르iguel.herrera@uai.cl

\title{
Mining
}

\section{Peculiarities of drilling and blasting in underground small-scale mines}

\begin{abstract}
Artisanal and Small-scale Mining (ASM) is a prominent activity in the extractive industry: considering only gold, it produces about $20 \%$ of the world market supply. Despite this fact, ASM is generally associated with the negative aspects of its environmental impact, and operational research is generally neglected. This article emphasizes the peculiarity of the drilling and blasting systems of small underground mines in selected South American Countries. Such Countries, while having large mineral deposits and well recognized large-scale mining activities, at the same time still present on their territory ASM activities that are archaic, highly inefficient and dangerous for the safety of its operators. This article documents drilling and blasting activities from gold mining in Ecuador and Chile. First, described are the outdated and often non-rational techniques employed by miners, to provide a general framework of the current methods. Then, shown is what can be improved and how the current methods can be modified. Finally, some field applications and the comparisons of the results obtained are presented. One case shows how blast pull efficiency can be increased from $82 \%$ to $98 \%$ by changing non-rational applications of explosive products to rational, scientific-based employment. Another case shows how, by rationalizing blast designs, drilling and blasting costs can be reduced by $9 \%$ per month, the advance by blasting increased by $29 \%$ and the pull efficiency increased from $70 \%$ to $90 \%$. Finally, it is concluded that examples of application show how operational improvements are easily applicable in the field, relying only on tools and resources of artisanal mining, but combining solid engineering bases with confidence-gain and respect for the experience of the miners.
\end{abstract}

Keywords: artisanal mining, underground mining, drill and blast.

\section{Introduction}

Mining is one of the oldest and most important industrial activities in the world, providing raw materials for the development of countries and generating jobs for millions of people. However, there is a mining sector whose sustainable and responsible development has been neglected due to the wide publicity of its negative social and environmental impacts. That sector is Artisanal and Small-scale Mining (ASM), which is present in every mining country in the developing world, and in cases like gold, contributes about $20 \%$ to world production (Seccatore et al., 2014a), a figure that is quite important, as commented in articles, such as Hilson, 2002; Seccatore et al, 2012, Marin et al. 2016. The ASM sector, lacking resources and capital access, compared to the medium and large mines of the world has not been able to evolve towards the state-of-the-art methods and technologies that are applied to- 
day (Andrew, 2003; Hentschel et al. 2003). The ASM way of working lacks an early exploration, feasibility studies and any kind of planning (Hruschka and Echavarría, 2011, Seccatore et al., 2013). Likewise, the methodologies, tools and technological applications of ASMs are often very outdated, obsolete, inefficient and unsafe most of the time because they are applied incorrectly (see Seccatore et al. 2014b). The line of work of underground ASM in the Andes region is basically based on drilling and blasting, and then, loading and transportation. Drilling and blasting are the most important activity, where miners suffer most of the problems, therefore where exists the most important opportunity to improve their work, achieving best practices, safety and profitability (Hentschel et al, 2002, Hruschka and Echavarría, 2011). The study presented herein was developed during R\&D projects in two mines in South America. The first, located in central Chile, is called Mina La Palmera and, the second, Golden Minera Comunitaria, in southern Ecuador. To conduct this study, we observed how each mine and its miners operate, understanding why they made certain decisions, eventually working with the miners to correct their mistakes and develop improvements.

\section{The chilean case}

The mine in Chile studied for this research is located in the $55^{\text {th }}$ mining district of Chancón, near the city of Rancagua, in the VI region, central Chile. Details regarding the Chancón district and its mining culture are described thoroughly in Espinoza et al.,
2020. In Chancón, along the years, the miners developed a very peculiar drilling and blasting pattern. A quite unusual diagram was observed at the early stages of the project, and it can be seen in Figure 1. After thorough observation of the miners' operations, it was determined that all the patterns met in the miners' firing diagrams were adaptations of a general one, that is presented in Figure 2. Curiously enough, the diagram does not employ any kind of opening cut, neither parallel holes nor inclined ones.
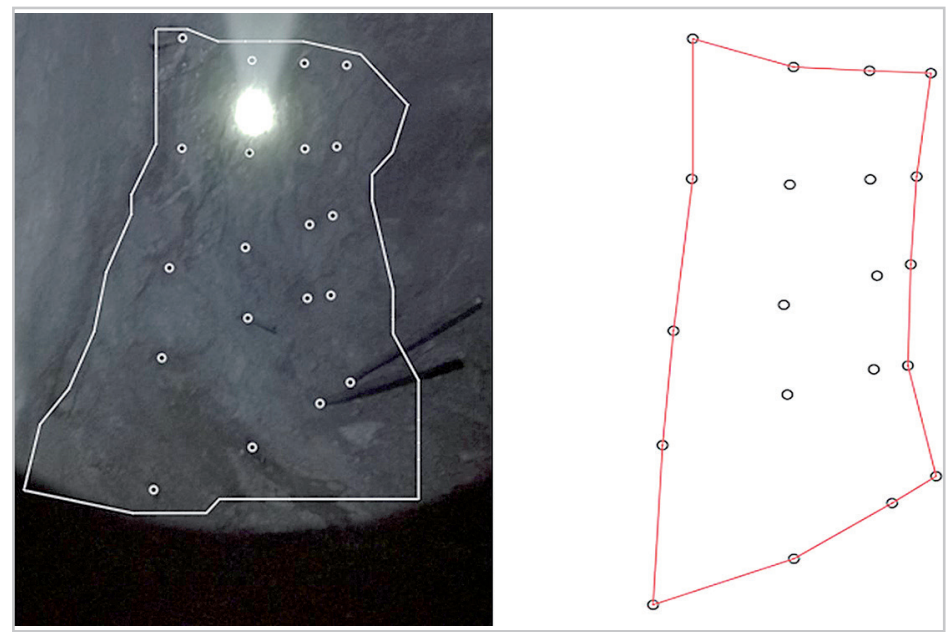

Figure 1 - La Palmera Mine' firing diagram.

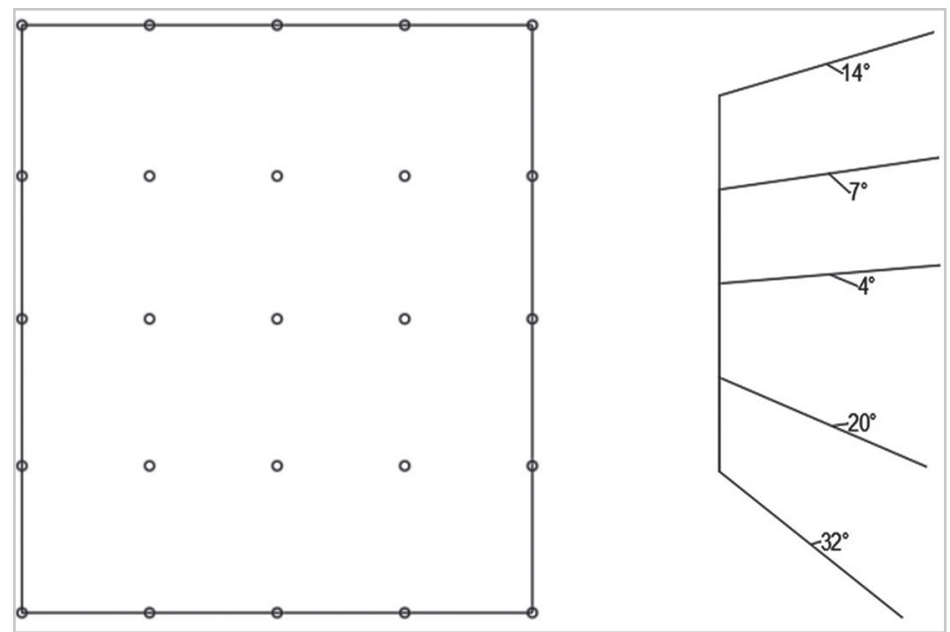

Figure 2 - Restructured La Palmera Mine' firing diagram in front and side view.

All the holes are loaded (no relief holes are employed) and, in addition, as the side view shows that the holes are drilled in an outward fan fashion, the opposite of a traditional V-shaped or pyramid-shaped open- ing cut. This implies that the efficiency is extremely poor, and the range of overbreak per shot is very extended and forced into the rock mass. During the research, a baseline survey was carried out, for which the follow- ing key performance indicators (KPIs) were considered: number of holes, drilling depth, average drilling time per hole, total drilling time, type of explosives, and total cost per blast. These data are reported in Table 1. 
Table 1 - Baseline drilling and blasting data, La Palmera Mine.

\begin{tabular}{c|c|c}
\hline Parameter & Value & Unit \\
\hline N. of holes & 25 & \# \\
\hline Drilling length (pull) & 1.6 & mm \\
\hline Drilling diameter & 38.1 & h: min: s \\
\hline Average drilling time per hole & $0: 03: 03$ & h: min: s \\
\hline Total drilling time & $2: 02: 00$ & \# \\
\hline Emulsion cartridges 1"X8" (25.4mm X203.2mm) & 25 & USD \\
\hline Cost of Emulsion & 14.75 & kg \\
\hline Anfo & 15 & USD \\
\hline Cost of Anfo & 16.22 & \# \\
\hline Fire cap + safety fuse & 25 & USD \\
\hline Cost of cap + fuse & 4.95 & USD \\
\hline Total Cost & & 25.92 \\
\hline
\end{tabular}

Table 1 shows that each hole is charged with one 1"x8" Emulsion cartridge (25.4mm X 203.2mm), 600 grams of ANFO and a detonator connected to 2.5 meters $(2.8 \mathrm{ft})$ strand of safety fuse. Due to the employment of a safety fuse, the blast is manually lit using a hand-size gas blowtorch, and the initiation sequence is determined by the blaster in charge. This firing sequence does not follow a standard pattern, and is mainly based on the blaster's sensibility, experience or mere custom. The authors of this study conducted burning tests of the fuse, in strands of $1 \mathrm{~m}$ each, sampled along a fuse coil. The results showed no variation in the burning speed, indicating that it can be considered constant along the coil. Fuse from one single coil is used in a single blast. Therefore, the initiation sequence depends on the ignition sequence of the fuses performed by the blaster with a blowtorch.

This randomness causes undesirable results, where the linear advance by blasting is approximately 1.12 meters (3.67 ft, achieved pull or actual pull), which is equivalent to $70 \%$ of the total drilled length (drilled pull or theoretical pull). It also stands out that, as a result of the fanned shots, there is obtained a total breaking envelope that presents up to $600 \%$ of overbreak, more than what was expected due to lookout angles up to $32^{\circ}$. In addition, the resulting granulometry is normally coarse and very uneven, since the distance between shots is very uneven itself. In turn, the drilling diameter is too small for ANFO, taking into account the critical diameter of the ANFO (normally considered around 2" or $50.1 \mathrm{~mm}$ ). The chance of the ANFO not properly detonating is severely high, and in fact the occurrence of misfires is quite common. In addition to that mentioned above, the mine has a heavy presence of water that runs through the tunnels, especially during the winter rainy season, generating critical conditions for the employment of ANFO. Figure 3 shows the dramatically poor result of a typical shot considering all the above-mentioned criticalities.

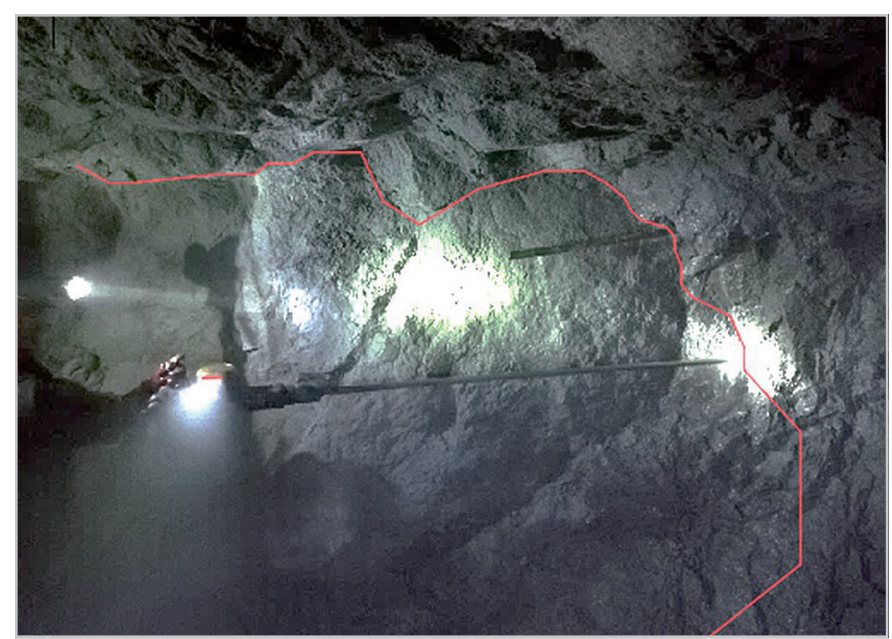

Figure 3 - Result of blasting at the Mina La Palmera,showing the overbreak profile.

To improve this situation, proper engineering methods for the design and realization of the blast were gradually applied. The drilling pattern was changed. Changing the drilling diameter was found to be an inconvenience by the miners, since the tools used could not be modified without capital investment unavailable to them. Therefore, the drilling diameter was kept at 1 " $1 / 2$ $(38.1 \mathrm{~mm})$ and the explosive agents were kept the same. This decision was made, besides the lack of resources, also to respect the fact that the miners distrust new practices, since they have always used a single work method all their life. To mitigate the rejection of the change, the miners were offered 
an integral solution, with engineering bases, but, above all, within the reach of what they could afford within the ASM framework. Each decision and calculation was studied considering Hustrulid and Bullock, 2001 and Hartman and Mutmansky, 2002. As for the changes that were made, it was proposed to prepare a shot diagram with standard dimensions being 2.3 meters $(7.55 \mathrm{ft}$ ) high and 2 meters $(6.56 \mathrm{ft})$ wide. Also, it was decided not to use the same amount of ANFO in each shot, but to separate the shots into functional sections (Table 2): Open cut in 3 rounds (Round 1, Round 2 and Round 3), Production Hole (Bottom, Top), Contour holes divided into Side holes, Crown holes and Floor holes. This allows the proper dosage of the amount of explosive used in each section, focusing on strong charges for demanding areas such as the floor, and a low amount of charge in light areas such as the crown and side sections. Simultaneously, a design based on parallel and completely horizontal open cut holes was delivered (Figure 4), which allows the granulometry of the rock resulting from the blasting to be more uniform. Also, the holes of the Crown, Side and Ground sections are drilled with an outlook of maximum $5^{\circ}$. This allows to reduce the break envelope by $600 \%$. The characteristics of the new proposed blast design are reported in Table 3.

Table 2 - ANFO distribution according to section ( $\mathrm{kg}-\mathrm{lb})$.

\begin{tabular}{c|c|c|c|c|c|c|c|c|c|c|c|c|c|c|c|c}
\hline Section & \multicolumn{2}{|c|}{ Round 1 } & \multicolumn{2}{c|}{ Round 2 } & \multicolumn{2}{c|}{ Round 3 } & \multicolumn{2}{c|}{ Prod. Top } & \multicolumn{2}{c|}{ Prod. Bottom } & \multicolumn{3}{c|}{ Sides } & \multicolumn{2}{c}{ Crown } & \multicolumn{2}{c}{ Floor } \\
\hline ANFO p/hole & 0.28 & 0.62 & 0.2 & 0.4 & 0.52 & 1.15 & 0.93 & 2.05 & 0.93 & 2.05 & 1.4 & 3.09 & 0.57 & 1.26 & 1.48 & 3.26 \\
\hline ANFO Total & 1.12 & 2.47 & 0.8 & 1.8 & 2.08 & 4.59 & 1.86 & 4.1 & 1.86 & 4.1 & 2.8 & 6.17 & 1.71 & 3.77 & 5.92 & 13.05 \\
\hline
\end{tabular}

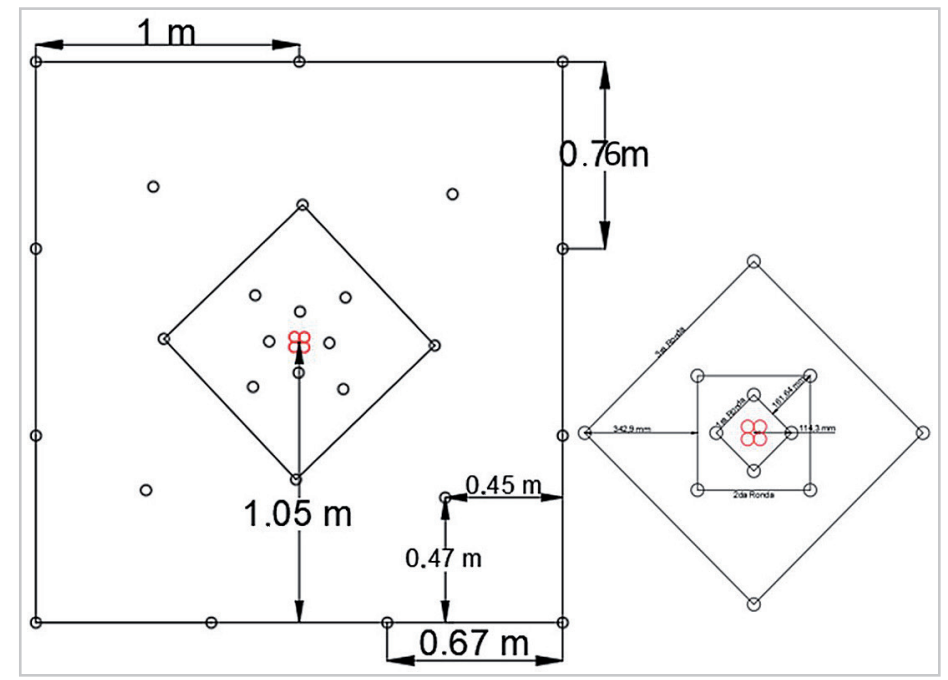

Figure 4 - Proposed blast design.

Table 3 - Proposed drilling and blasting data.

\begin{tabular}{c|c|c}
\hline Parameter & Value & Unit \\
\hline N. of holes & 28 & $\#$ \\
\hline Drilling length (pull) & 1.6 & $\mathrm{~m}$ \\
\hline Drilling diameter & 38.1 & $\mathrm{~mm}$ \\
\hline Average drilling time per hole & $0: 03: 03$ & $\mathrm{~h}: \mathrm{min}: \mathrm{s}$ \\
\hline Total drilling time & $2: 21: 31$ & $\mathrm{~h}: \mathrm{min}: \mathrm{s}$ \\
\hline Emulsion cartridges 1"X8" (25.4mm X 203.2mm) & 28 & $\#$ \\
\hline Cost of Emulsion & 16.19 & USD \\
\hline Anfo & 18.15 & $\mathrm{~kg}$ \\
\hline Cost of Anfo & 19.26 & USD \\
\hline Fire cap + safety fuse & 28 & $\#$ \\
\hline Cost of cap + fuse & 5.44 & USD \\
\hline Total Cost & 40.89 & USD \\
\hline
\end{tabular}

The results of the new proposed blast is shown in Figure 5.
- $90 \%$ of pull efficiency was obtained

- Overbreak reduced by $600 \%$
- Clean contour

- Fine and uniform granulometry 


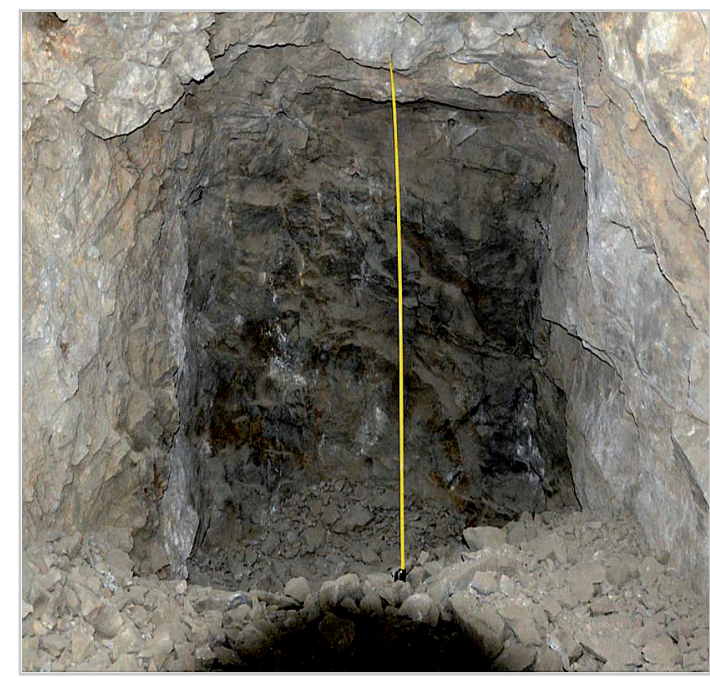

Figure 5 - Result of the new proposed blast.

\section{The ecuadorian case}

The mine studied in Ecuador, Golden Minera Comunitaria, is located in the Zaruma-Portovelo mining district, in the province of El Oro, southern Ecuador. Technical aspects of drilling and blasting in these mines have already been documented by Seccatore et al. 2014b. Other economic and strategic aspects of the mines of this area are described in detail in Seccatore et al., 2013 and Marin et al., 2016 and Sandoval, 2001. The R\&D project developed in this mine was a training course on drilling and blasting techniques within the framework of a larger project of capacity-building for small-scale and artisanal miners in Ecuador. To understand the local miners' practices and evaluate possible im- provements, it was decided to perform three different blasts, where practices by miners, a consulting company and a national explosives manufacturer could be compared.

- Blast n.1: in its entirety drilled, charged and fired by local miners, according to their tradition and employing the tools and explosive agents typically used in the area. Shown in Figure 6.

- Blast n.2: drilling diagram based on rational methods studied by the contracted consulting firm, however, employing the same tools and explosive agents typically used in the areas in Blast 1. Shown in Figure 7.

- Blast n.3: drilling pattern determined by the contracted consulting firm, on the basis of engineering design methods, employing modern explosives and initiation devices provided by the national explosives manufacturer.

Local miners typically employ a column charge of hand-made cartridges of Ammonium Nitrate (AN, without Fuel Oil, in drills: This is because the ventilation time decreases and, despite having a lower VOD, the shock wave manages to fracture the rock; detail in Seccatore et al. 2014b) rolled in newspaper foils, boosted by one cartridge of Dynamite $60 \%$ NGL as bottom charge, in its turned primed by a fire cap n.8. The good fragmentation obtained suggests that AN detonates when ignited by dynamite. Nevertheless, VOD recording proved unfeasible during this study.

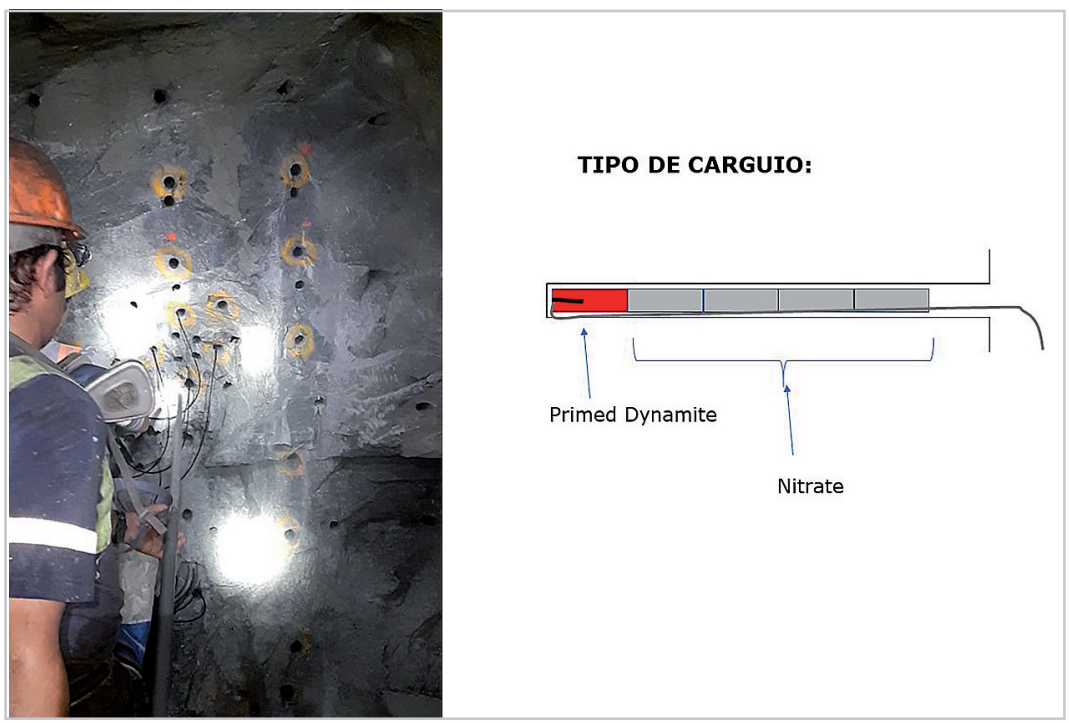

Figure 6 - Blast 1: drilling and charging configuration. 


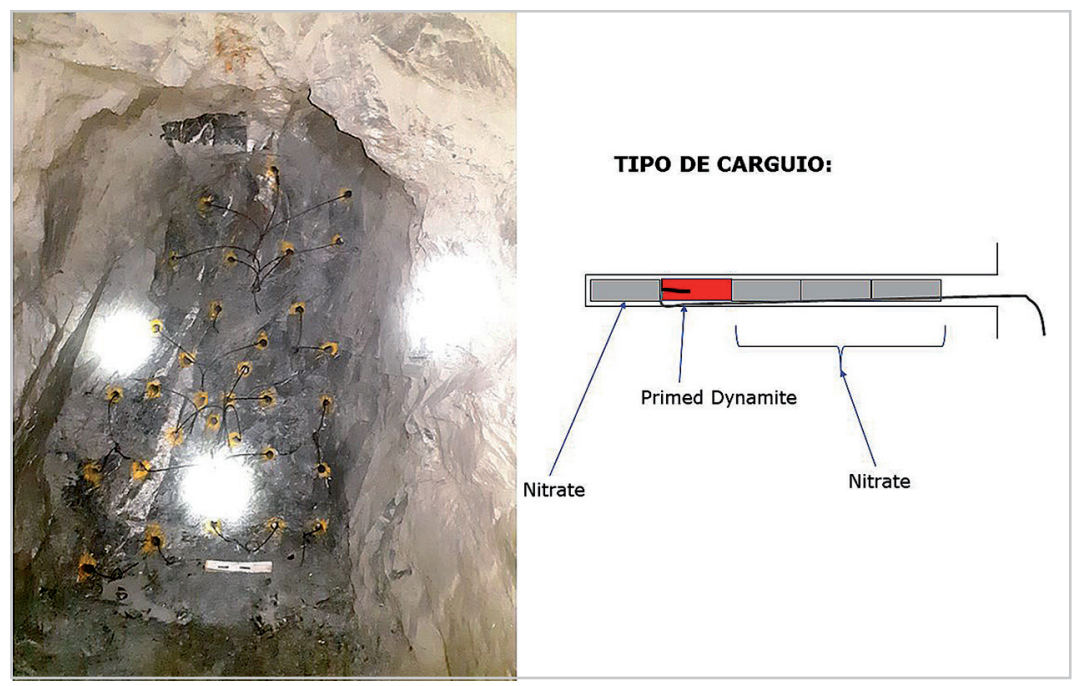

Figure 7 - Blast 2: drilling and charging configuration.

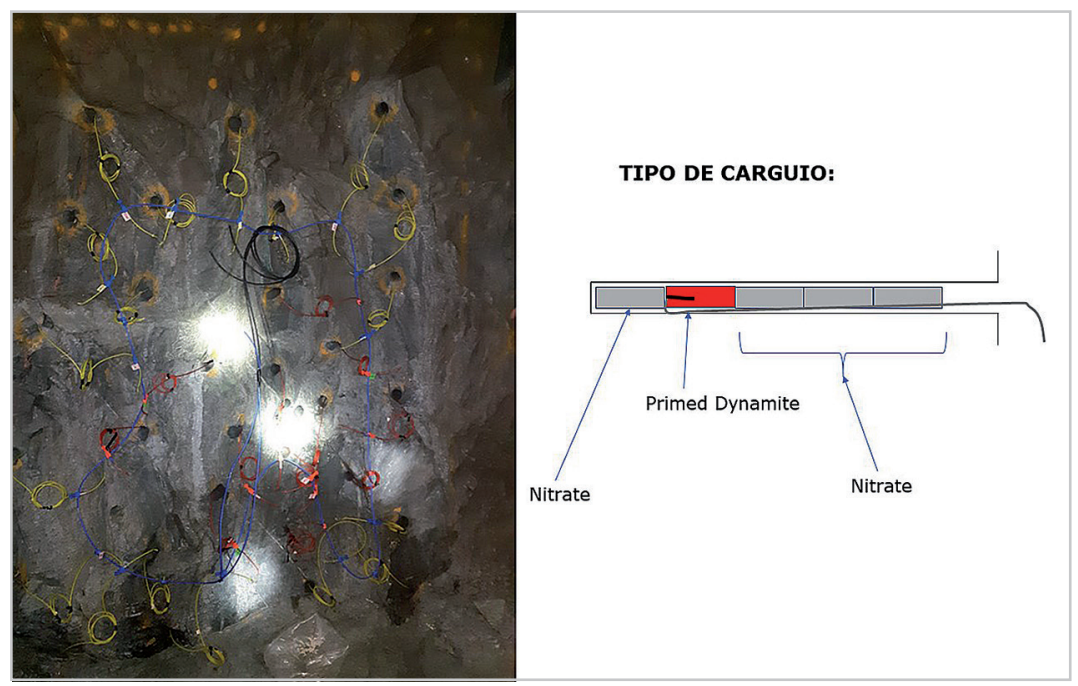

Figure 8 - Blast 3: drilling and charging configuration.

One must note that the drilling and charging were always performed by local miners. As shown in Figures 6, 7 and 8:

- Blast 1 had the dynamite primer correctly located at the bottom of the hole, that breaks the toe by advantage of the high VOD of dynamite

- Blast 2 and 3 employed an irrational positioning of the dynamite primer, second in order after a cartridge of AN, that provides a very low detonation shockwave if any at the very toe, the hardest point to break.

The irrational charging method of blasts 2 and 3 had already been observed as commonly employed by the authors of this study during field research in 2012 and 2013. It is still unknown whether the irrational charging was employed in the blasts designed by the external contractor on purpose to discredit their work, or by mere chance of operational habit of the miners that prepared those blasts. Results of the 3 blasts are shown in Figure 9 and numerical results reported in Table 4 . The main conclusion drawn both by the miners and the R\&D team for this project was that, with a good degree of surprise, the blasting system developed over the years by the miners, with the shared experience of the local mining community and the empirical knowledge of the local geology, has allowed to reach $98 \%$ pull efficiency; on the other hand, the blasting system prepared by the contractor and the explosives manufacturer, based on scientific and rational methods, without prior knowledge of local geology and local rock-explosive interactions, has reached an average of $83 \%$ efficiency at the first attempt, despite the irrational charging method employed. Both the miners and the contractor concluded that shared experience and open-minded attitude, prone to accept changes and adapt, is the key for success in this kind of project.

Table 4 - Compared results of the 3 blasts.

\begin{tabular}{c|c|c|c}
\hline \multicolumn{2}{|c|}{ Pull efficiency } & Overbreak & Underbreak \\
\hline Blast 1 & $98,16 \%$ & No & Yes \\
\hline Blast 2 & $82,07 \%$ & No & Yes \\
\hline Blast 3 & $85,36 \%$ & Yes & No \\
\hline
\end{tabular}




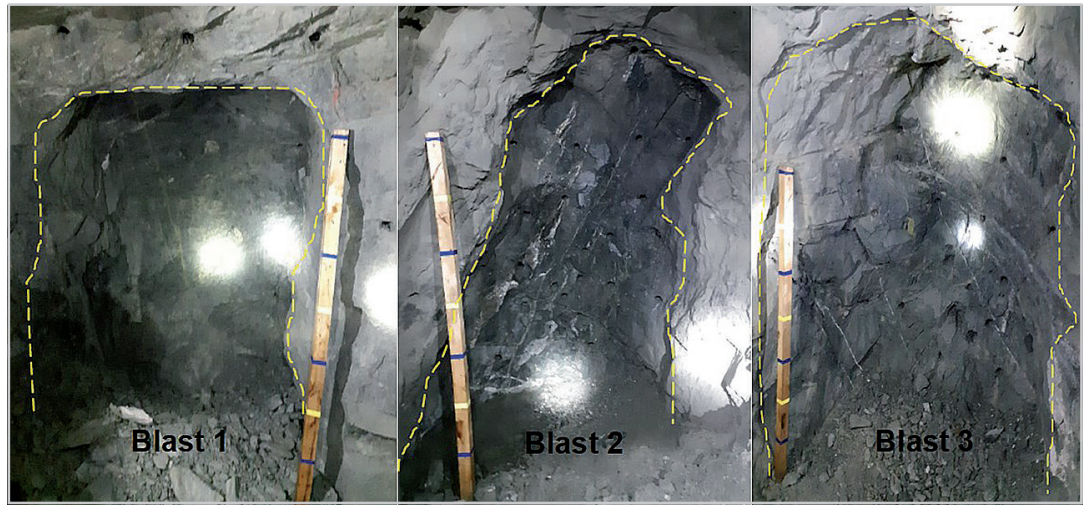

Figure 9 - Compared visual results of the 3 blasts.

\section{Discussion on short-term vision of ASM}

In the Chilean study, it was found that the application of rational and engineering-based methods allowed to increase the blasting pull efficiency from $70 \%$ to $90 \%$. Following this premise, an analysis was on 20 blastings, the equivalent of one month of work, using both methods. The results are shown in Figures
10 and 11. It is seen that the base blasting (with ASM method) has an advance of $22.4 \mathrm{~m}(73.5 \mathrm{ft})$ over 20 rounds, and an associated cost of 718 USD compared to an advance of $28.8 \mathrm{~m}(94.5 \mathrm{ft})$ at a cost of 818 USD in the proposed blasting (with engineering methods). For the short-sighted view of ASM operators, this seems cheaper, therefore the best option. Nevertheless, looking at a monthly term, tunnel advance is higher by $29 \%$ applying the proposed blast design, and, if an analysis of the true cost per meter is made, it can be observed that the proposed blasting has a monthly saving of $9 \%$ compared to base blasting.

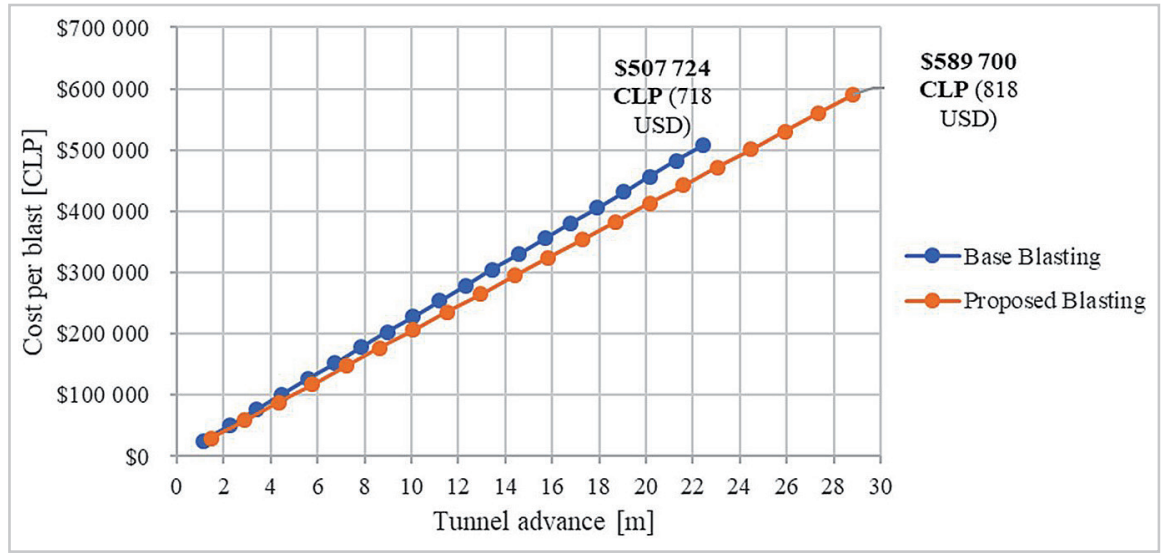

Figure 10 - Cost per blast over 20 blasts.

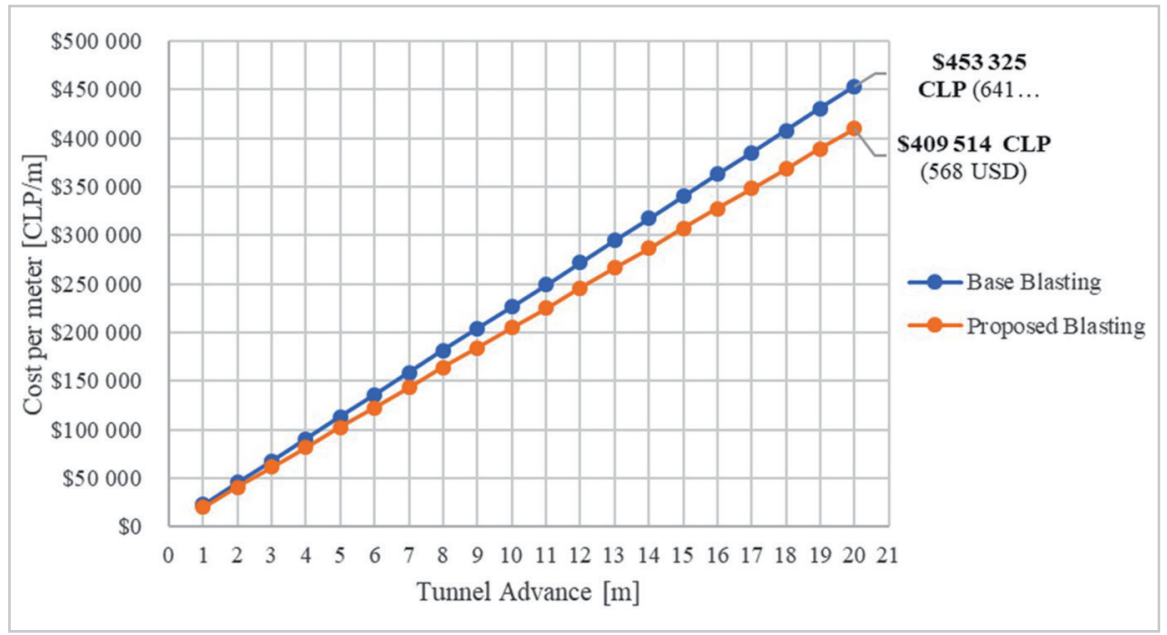

Figure 11 - Cost per meter excavated, over 20 blasts.

\section{Conclusions}

This article deals with the application of engineering methods in a critical environ- ment such as ASM. This is a very important opportunity for the development of this mining sector, which due to lack of resources and tools has not been able to evolve or 
grow as expected and deserved. Every great work starts from the smallest source, so the empirical knowledge that ASM miners have about the qualities and the behavior of the rock mass is a wealth that many times the rigorous engineering methods would be unable to obtain without important capital investment. To achieve significant changes and success cases, both ends of the collaboration chain, R\&D developers on one side and artisanal miners on the other, must be able to keep a proactive, collaborative attitude and be ready to learn one from the other. As seen in the studies of Chile and
Ecuador, understanding the very source of issues and collaboration to overcome them is the key to achieve a significant change in artisanal and small-scale mining and in the application of field engineering where perfect circumstances do not exist, but risk and uncertainty are constantly present.

\section{References}

ANDREW, J. S. Potential application of mediation to land use conflicts in small-scale mining. J. Clean. Prod. v. 11, n.2, p.117-130, 2003.

ESPINOZA, C.; SECCATORE, J.; HERRERA, M. (2020) Chilean artisanal mining: a gambling scenario. REM: International Engineering Journal, v. 73, n.2, p. 241-246, Apr./June 2020.

HARTMAN, H. L.; MUTMANSKY, J. M. Introductory mining engineering. [S. l.]: John Wiley e Sons, 2002. p. 267-322.

HENTSHEL, T; HRUSHKA, F; PRIESTER, M. Global report on artisanal \& small-scale mining. London: IIED, WBCSD, January 2002. (Mining, Minerals and Sustainable Development, n.70).

HENTSCHEL, T.; HRUSCHKA, F.; PRIESTER, M. Artisanal and small-scale mining: challenges and opportunities. London: IIED, WBCSD, 2003. (Mining, Minerals and Sustainable Development).

HILSON, G. Small-scale mining and its socio-economic impact in developing countries. Natural Resources Forum, v. 26, n.1, p. 2-13, 2002.

HRUSCHKA, F.; ECHAVARRÍA, C. Rock solid chances for responsible artisanal mining. Medellín: Alliance for Responsible Mining, ARM, 2011. (ARM Series on Responsible ASM, n. 3). ISBN 978-958-99798-0-8.

HUSTRULID, W. A.; BULLOCK, R. L. (ed.). Underground mining methods: engineering fundamentals and international case studies. [S. 1.]: SME, 2001. p. 635-662. ISBN 9780873351935.

MARIN, T.; SECCATORE, J.; DE TOMI, G.; VEIGA, M. Economic feasibility of responsible small-scale gold mining. Journal of Cleaner Production, v. 129, p. 531-536, 15 aug. 2016.

SANDOVAL, F. La pequeña minería en el Ecuador. London: IIED, WBCSD, 2001. (Mining, Minerals and Sustainable Development, n.75).

SECCATORE, J.; DE TOMI, G.; VEIGA, M. Efficiency as a road to sustainability in small-scale mining. In: INTERNATIONAL CONFERENCE ON INTELLIGENCE PROCESSING AND MANUFACTURING OF MATERIALS, 7th., September 2-3, 2012, Foz de Iguaçu, Brazil. Proceedings [...]. Foz do Iguaçu: IPMM, 2012.

SECCATORE, J.; MARIN, T.; VEIGA, M.; DE TOMI, G. A practical approach for the management of resources and reserves in Small-Scale Mining. Journal of Cleaner Production, n. 84, p. 803-808, 2013.

SECCATORE, J.; VEIGA, M.; ORIGLIASSO, C.; MARIN, T.; DE TOMI, G. An estimation of the artisanal small-scale production of gold in the world. Science of the Total Environment, v. 496, p. 662-667, 2014a.

SECCATORE, J.; MAGNY, L.; DE TOMI, G. Technical and operational aspects of tunnel rounds in artisanal underground mining. REM - Revista Escola de Minas, v. 67, n. 3, p. 303-310, 2014b.

Received: 1 January 2020 - Accepted: 9 March 2020. 